\title{
Thermal Performance of Structural Lightweight Concrete Composites for Potential Energy Saving
}

\author{
Yeong Huei Lee ${ }^{1}$, Nicholas Chua ${ }^{1}$, Mugahed Amran ${ }^{2,3, *}$, Yee Yong Lee ${ }^{4} \oplus$, Ahmad Beng Hong Kueh ${ }^{4}{ }^{\oplus}$, \\ Roman Fediuk $^{5}\left(\mathbb{D}\right.$, Nikolai Vatin ${ }^{6}(\mathbb{D})$ and Yuriy Vasilev ${ }^{6}$
}

1 Department of Civil and Construction Engineering, Faculty of Engineering and Science, Curtin University, Sarawak Malaysia, CDT 250, 98009 Miri, Sarawak, Malaysia; yhlee@civil.my (Y.H.L.); 700017788@student.curtin.edu.my (N.C.)

2 Department of Civil Engineering, College of Engineering, Prince Sattam Bin Abdulaziz University, Alkharj 11942, Saudi Arabia

3 Department of Civil Engineering, Faculty of Engineering and IT, Amran University, Amran 9677, Yemen

4 Department of Civil Engineering, Faculty of Engineering, Universiti Malaysia Sarawak, 94300 Kota Samarahan, Sarawak, Malaysia; yylee@unimas.my (Y.Y.L.); kbhahmad@unimas.my (A.B.H.K.)

5 Polytechnic Institute, Far Eastern Federal University, 690922 Vladivostok, Russia; fedyuk.rs@dvfu.ru

6 Moscow Automobile and Road Construction University, 125319 Moscow, Russia; vatin@mail.ru (N.V.); yu.vasilev@madi.ru (Y.V.)

* Correspondence: m.amran@psau.edu.sa or mugahed_amran@hotmail.com

check for updates

Citation: Lee, Y.H.; Chua, N.; Amran, M.; Yong Lee, Y.; Hong Kueh, A.B.; Fediuk, R.; Vatin, N.; Vasilev, Y. Thermal Performance of Structural Lightweight Concrete Composites for Potential Energy Saving. Crystals 2021, 11, 461. https://doi.org/ $10.3390 /$ cryst11050461

Academic Editor:

Yurii Barabanshchikov

Received: 18 March 2021

Accepted: 17 April 2021

Published: 21 April 2021

Publisher's Note: MDPI stays neutral with regard to jurisdictional claims in published maps and institutional affiliations.

Copyright: (c) 2021 by the authors. Licensee MDPI, Basel, Switzerland. This article is an open access article distributed under the terms and conditions of the Creative Commons Attribution (CC BY) license (https:// creativecommons.org/licenses/by/ $4.0 /)$.

\begin{abstract}
Residential consumption dominates the energy expenditure of heating and cooling systems, especially in tropical climates where building envelopes play an important role in energy efficiency. The thermal properties of concrete that are commonly employed as the building envelope material affect directly human comfort in a building. In addressing both the concrete thermal performance and industrial waste issues, this paper experimentally studies the concrete compressive strength and thermal properties used later for comparative energy analysis for human comfort. Four design mixes and a conventional concrete as control specimen are considered utilizing industrial wastes; palm oil fly ash (POFA), lightweight expanded clay aggregate (LECA), oil palm shell (OPS), and quarry dust, as constituents. These mixes are cast for cube compressive strength (to ensure the achievement of structural concrete requirement) and small-scaled wall tests. The measurement of surface temperatures of scaled wall tests is conducted in a polystyrene box to determine the concrete time lag and decrement factor. It is found that the density of concrete governs the compressive strength and that air pockets in the concrete matrix play an essential role as far as the thermal properties are concerned. From the energy analysis, structural lightweight concrete may save approximately $50 \%$ of the residential energy consumption.
\end{abstract}

Keywords: thermal behavior; time lag; decrement factor; energy consumption; concrete

\section{Introduction}

The rapid growth and diversification of various appealing economic developments by urbanization are symbiotically accelerated by the massive migration towards city or metropolitan areas for a better lifestyle, in which there is an increased trend of the human population. This pattern of population agglomeration is often synonymous with intensified utilization of energy that results in heavy heat release. The use of impermeable surfaces as construction materials within the urban areas promote, more so the trapping of the generated heat creating the urban heat island (UHI) phenomenon with an ambient temperature greater than the surrounding sites, the situation of which demands more energy to achieve indoor human comfort. Furthermore, the tendency of commonly employed 
building materials, such as concrete, to store heat energy, in terms of high specific heat property, directly contributes to the UHI issue [1].

In the tropics, the hot and humid conditions require concrete properties to be of low thermal conductivity and specific heat to reduce energy consumption for better building performance. Thus, energies that are consumed in tropics are predominant in assessing the building performance specifically pertaining to the human indoor thermal comfort. From studies, approximately $60-80 \%$ of total residential energy was typically utilized for heating and cooling systems [2]. Therefore, heat transfer through the building envelope is the primary element governing residential energy consumption. Aside from thermal properties, concretes can be divided into structural and non-structural use according to their load-bearing characteristics. Their load-carrying behaviors for structural uses are defined by the requirements of codes of practice. In the variety of available concrete material technologies, lightweight concretes, which include foamed concrete [3-5], oil palm shell concrete [6,7], and lightweight aggregate concrete [8,9], offer alternative options for building materials by achieving the constraint of structural use. For this, ACI design specification has identified a minimum compressive strength of $17 \mathrm{MPa}$. So long as this requirement is satisfied, many design mixes can achieve structural concrete functionality with a low concrete hardened density.

It is revealed, from the existing investigations, that the heat flux fluctuation was governed by the thermal capacity of wall building materials [10]. To examine the thermal behaviors of building materials in the building envelope, time lag and decrement factor that are determined from the indoor and outdoor surface temperatures are the main parameters of concern. As heat propagates through the concrete wall, the manner the heat amplitude decreases is referred as the decrement factor $(f)$, while the time delay is known as time lag $(\varphi)$. These parameters relate to the thermal comfort evaluation of the building envelope and, in turn, relate to the energy consumption response of building materials. Thermal comfort can be attained with building materials of high time lag and low decrement factor. Thus, these dynamic thermal characteristics have been studied, specifically for lightweight concrete [11-14], earth bricks [15], thermal insulation concrete [16], reinforced mortar channels [17], building element of the wall [18], etc. The voids within the concrete are able to resist the thermal transfer from outdoor to indoor. The thickness of the insulation void layer in a glass panel was able to increase the time lag and reduce the decrement factor [19].

Under the categorization of lightweight concretes, various materials, including those from industrial waste, have been potentially considered to be the principal constituents. As some of the largest global exporters of palm oil, for instance, Malaysia and Indonesia, the wastes from the agro-industries of these countries are relatively more, hence, need proper management of their disposal. Because palm oil fly ash (POFA) and oil palm shells from this industry are well-known as cementitious Supplementary Materials to provide concrete strength, they can be incorporated into concrete to solve the problem of waste. Moreover, other industrial wastes, like quarry dust, can be reduced from uncontrolled environmental exposure by introducing them into the concrete matrix. Besides, utilizing artificial aggregate, like lightweight expanded clay aggregate (LECA), may lessen the threat of natural resource depletion. It has been highlighted the positive attributes of the oil palm shell, quarry dust, and LECA materials; thus, this study aims to improve the mechanical and thermal properties of concrete composites towards sustainable concrete production for the prospect in building material applications, in particular, for thermal comfort purposes. In particular, the time lag and decrement factor of these concretes were examined. Furthermore, small-scaled walls were cast with the proposed design mixes to obtain the surface temperatures for further analysis. Simple energy analysis was then conducted in order to compare these structural concretes in terms of their ranking as material for low energy consumption. 


\section{Investigation Procedures}

There are two main investigation procedures, namely experimental program and energy consumption calculation. Strength and scaled wall tests were considered in the experimental program. The potential design mixes were cast to firstly pass the strength tests for further scaled wall investigations. The thermal behaviors of the structural lightweight aggregate concrete were then used for the simple energy consumption analysis for the final performance appraisal.

\subsection{Specimen Preparation}

There were four design mixes proposed in this investigation for structural lightweight aggregate concrete and one conventional design mix as the control. These mixes were proposed optimally by referring to previous studies [20-22]. Table 1 lists the material proportions of the proposed structural concrete design mixes. The water-cement ratio for all mixes was fixed at 0.5 . The concrete matrices contained the raw materials. as described in the following.

Table 1. Mix proportion in $\mathrm{kg}$.

\begin{tabular}{ccccccccc}
\hline \multirow{2}{*}{ Mix } & \multicolumn{3}{c}{ Binder } & \multicolumn{3}{c}{ Coarse Aggregate } & \multicolumn{2}{c}{ Fine Aggregates } \\
\cline { 2 - 9 } & OPC & G-POFA & U-POFA & LECA & OPS & Gravel & Sand & Quarry Dust \\
\hline Conventional & 5.11 & - & - & - & - & 8.95 & 4.54 & - \\
G-POFA & 4.60 & 0.28 & - & - & - & 8.95 & 4.54 & - \\
U-POFA & 4.09 & - & 0.69 & - & - & 8.95 & 4.54 & - \\
25-LECA \& 75-OPS & 5.11 & - & - & 0.64 & 2.88 & - & 4.54 & - \\
OPS \& 50-QD & 5.11 & - & - & - & 3.83 & - & 2.27 & 2.16 \\
\hline
\end{tabular}

\section{Materials}

Ordinary Portland cement (OPC) that was obtained is a local. POFA-considered as the supplementary cementitious material, with the required properties of passing through $45 \mu \mathrm{m}$ and heat-treated in $500^{\circ} \mathrm{C}$ to produce G-POFA with $880 \mathrm{~kg} / \mathrm{m}^{3}$ density. G-POFA was further ground to obtain ultrafine POFA (U-POFA), with $1080 \mathrm{~kg} / \mathrm{m}^{3}$ density. LECA-a locally obtained material that strictly followed the specification of ASTM C 33 for coarse aggregate, with sizes ranging from 9.5 to $37.5 \mathrm{~mm}$. OPS was employed as the coarse aggregate replacement, which also complied with ASTM C 33 for the sizing. Quarry dust (QD) - density of $1350 \mathrm{~kg} / \mathrm{m}^{3}$ and sieved to maintain its fineness modulus range of 2.3 to 3.1. River sand-density of $1420 \mathrm{~kg} / \mathrm{m}^{3}$. Figure 1 shows the materials in the concrete mix.

Because of the hydrophilic behavior of LECA and OPS, they affect the water-cement ratio and cause internal cracks that weaken the concrete strength [23]. Hence, the saturated surface drying was conducted by pre-soaking these aggregates. In this investigation, LECA and OPS were pre-soaked $24 \mathrm{~h}$ before the casting process. $100 \times 100 \times 100 \mathrm{~mm}$ cubes were adopted for the strength test, while the scaled wall test consisted of a specimen size of $300 \times 300 \times 102.5 \mathrm{~mm}$ (as shown in Figure 2), the dimension of which was determined following the thickness of brick by the Malaysian specification. The specimens were water cured for 28 days before the tests were conducted. 


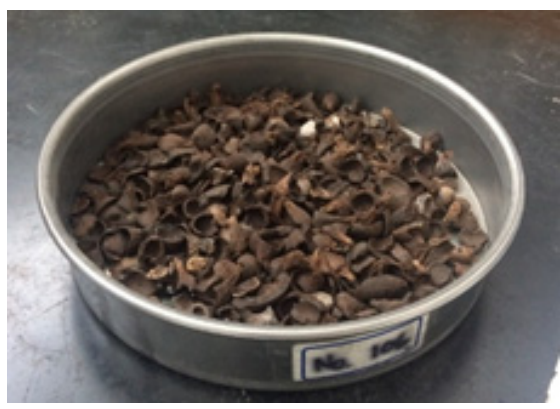

(a)

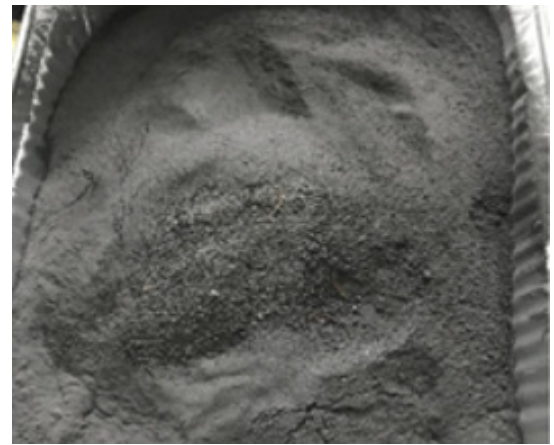

(c)

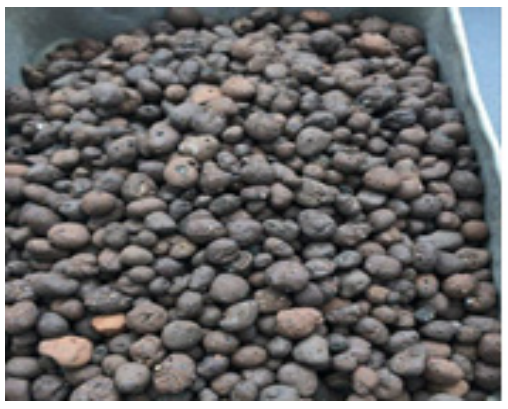

(b)

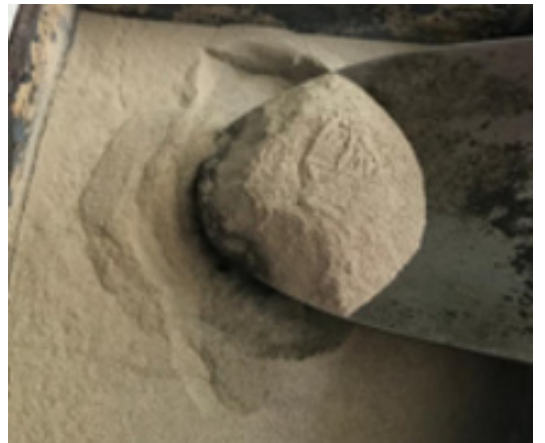

(d)

Figure 1. The materials in concrete casting: (a) OPS, (b) LECA, (c) G-POFA, and (d) U-POFA.

$102 \mathrm{~mm}$

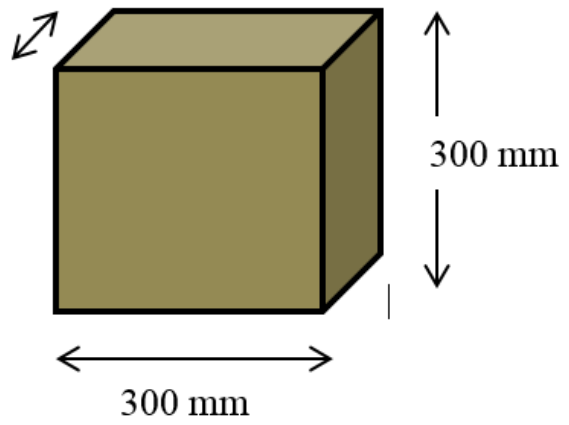

Figure 2. Sketch up of the small-scaled wall specimen.

\subsection{Test Procedures and Methods}

2.2.1. Strength Test

The cubes were dried at $105^{\circ} \mathrm{C}$ in an oven for two hours after 28 days of curing period. A compressive strength test was conducted in compliance with the ASTM C 39 specifications. Loading rates of 0.14 to $0.34 \mathrm{MPa} / \mathrm{sec}$ were adopted for the strength evaluation using the universal testing machine.

\subsubsection{Scaled Wall Test}

Scaled wall specimens were used to measure the surface temperatures of the considered mixes in a controlled environment. There is currently no established test procedure; hence, a polystyrene box was constructed in order to quantify the temperatures of both wall surfaces of each specimen. Figure 3 shows the experimental setup. Thermocouple type $\mathrm{T}$ and HOBO data logger (USA product) were used to record the wall surface temperatures. To run the test, one wall surface was exposed to the radiation of a 60-Watt light bulb, while the other sides were covered up by polystyrene wrapped with aluminum foil. At the preliminary stage, it was found that a high temperature of $65{ }^{\circ} \mathrm{C}$ could be reached on the normal-weight concrete surface. During the tests, the light bulb is switched on for five 
hours to achieve the maximum wall surface temperature and then switched off for the natural cooling process to reach room ambient temperature.

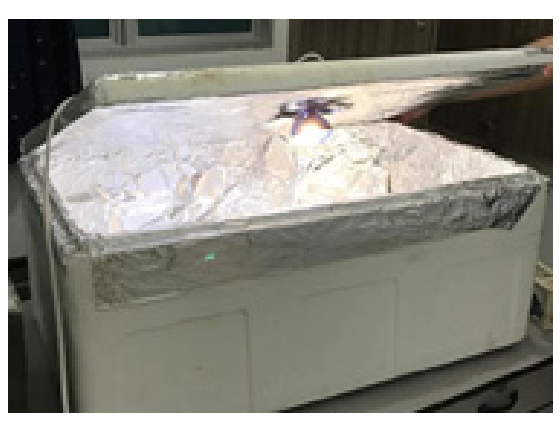

(a)

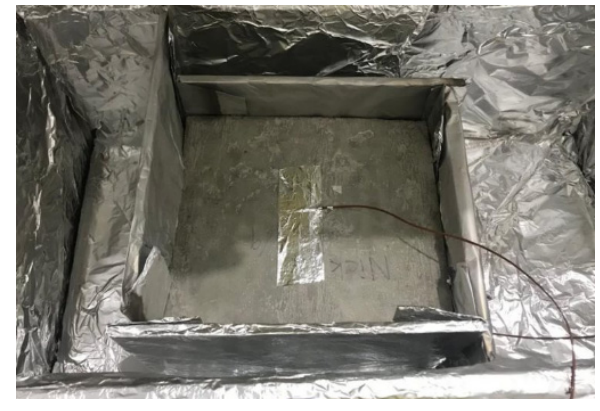

(b)

Figure 3. (a) Experimental setup and (b) specimen of the thermal scaled wall test.

\subsection{Energy Consumption Calculation}

\subsubsection{Calculation Model}

Not being restricted to developing countries, the energy consumption has shown an increasing trend from year to year where it is related to inevitable fossil fuel is used for energy generation. As an initiation, American Society of heating, Refrigerating and Air-conditioning Engineers (ASHRAE) has created the concept of Overall Thermal Transfer Value (OTTV), as an indicator of thermal performance of the air-conditioned commercial buildings' envelope. Malaysia adopted OTTV as an energy standard for commercial building in late $80^{\prime}$ s after Singapore implemented their own energy code of Building Energy Standard (BES) through building service regulations. There are three heat transfers, from outside to indoor, which have been identified, including opaque surface conduction, glass conduction, and solar radiation through glass. The OTTV general equation has been shown in Equation (1) and Malaysian experience is shown in Equation (2) [24]. It has a slight difference from MS1525 part 5 [25] for non-residential buildings.

$$
\begin{gathered}
\text { OTTV }=\frac{Q_{w}+Q_{g}+Q_{s}}{A_{i}} \\
\text { OTTV }=19.1 \propto \times(1-\mathrm{WWR}) \times U_{w}+194 \times \mathrm{WWR} \times S C
\end{gathered}
$$

where $Q_{w}$ is the opaque surface conduction, $Q_{g}$ is the glass conduction, $Q_{s}$ is the solar radiation, $\alpha$ is the solar absorption coefficient, $U_{w}$ is the wall conductivity value, WWR is the window to gross wall ratio, and $S C$ is the shading coefficient.

Because air conditioners are the main residential energy consumption, this proposed calculation model is based on cooling load analysis. Similar to the OTTV, total cooling load can be represented by Equation (3).

$$
Q_{\text {cool }}(t)=Q_{t}+Q_{s}+Q_{s l}+Q_{\text {lat }}+Q_{\text {int }}
$$

where $Q_{t}$ is the transmission load, $Q_{s}$ is the solar load, $Q_{s l}$ is the sensitive load, $Q_{\text {lat }}$ is the latent load, and $Q_{i n t}$ is the internal load. The transmission load can be written as Equation (4).

$$
Q_{t}=\mathrm{US}\left(T_{o}-T_{i}\right)
$$

where $\mathrm{U}$ is the heat transfer constant in $\mathrm{W} / \mathrm{m}^{2} \mathrm{~K}, \mathrm{~S}$ is the transmission area in $\mathrm{m}^{2}$, and $\left(T_{o}-T_{i}\right)$ is the temperature difference between outdoor and indoor.

\subsubsection{Case Study}

The energy consumption estimation of South Africa was modeled in [26], where the referred temperature was set at $22{ }^{\circ} \mathrm{C}$, dictating a rise of $8 \%$ energy usage from each 
degree increment in ambient temperature. The calculation model involved cooling load (transmission, infiltration, solar, and internal loads) and energy consumption calculation. Using the maximum outdoor temperature of $32{ }^{\circ} \mathrm{C}$ as a reference, one degree Celsius of decrement in the indoor temperature yields a decrement factor of $3.125 \%$. Therefore, the indoor temperature of an enclosed unit could experience a reduction of up to $1{ }^{\circ} \mathrm{C}$ for each $3.125 \%$ of decrement factor that is possessed by the external wall of the unit. Theoretically, for each $3.125 \%$ decrement factor of the external wall, the enclosed unit holds the potential for $8 \%$ of energy saving in terms of cooling services.

\section{Results and Discussions}

The compressive strength and thermal behavior of the proposed design mixes were first captured and then analyzed in the following sections.

\subsection{Compressive Strength}

Concrete cement replacement with POFA had almost the same density when compared to conventional concrete, where only a $5 \%$ weight decrement was found, as shown in Table 2. Lower densities of LECA and OPS as coarse aggregates replacement resulted in relatively low weight and compressive strength. Higher weight or density typically produce a higher strength because the compressive strength is correlated with density. It is found from the table that all of the proposed design mixes achieved at least the minimum structural concrete strength of $17 \mathrm{MPa}$ as specified by the ACI code of practice. Accordingly, the application of these proposed design mixes satisfies the strength requirement as structural members in resisting loadings.

Table 2. Weight, density, and compressive strength of proposed design mixes.

\begin{tabular}{cccc}
\hline Specimen & Weight $\mathbf{( k g )}$ & $\begin{array}{c}\text { Oven-Dry Density at } \\
\text { 28 Days } \mathbf{( k g / \mathbf { m } ^ { 3 } )}\end{array}$ & $\begin{array}{c}\text { Compressive } \\
\text { Strength } \mathbf{( M P a})\end{array}$ \\
\hline Conventional & 2.48 & 2480 & 56.1 \\
U-POFA & 2.36 & 2360 & 55.3 \\
G-POFA & 2.34 & 2340 & 52.4 \\
25-LECA 75-OPS & 1.78 & 1780 & 17.2 \\
OPS 50-Quarry Dust & 1.88 & 1880 & 19.3 \\
\hline
\end{tabular}

\subsection{Thermal Performance}

The thermal performance of the proposed design mixes was assessed through the surface temperature measurement in a polystyrene box-controlled environment and a light bulb as the heat source, as readily described in Section 2.2.2. The thickness of the small-scaled wall was fixed at $102.5 \mathrm{~mm}$, a brick thickness. The surface that was exposed to the light bulb was defined as the exterior surface, while that insulated with polystyrene was the interior wall surface. Table 3 summarizes the recorded thermal data for all considered mixes as compared to a brick wall of a residential house as the control case. Figure 4 shows the external and internal temperatures of the proposed mixes.

Table 3. Time lag and decrement factor of the walls of proposed design mixes and a residential house.

\begin{tabular}{|c|c|c|c|c|}
\hline \multirow{2}{*}{ Specimen } & \multicolumn{2}{|c|}{ Max. Surface Temperature, ${ }^{\circ} \mathrm{C}$} & \multirow{2}{*}{$\begin{array}{l}\text { Decrement } \\
\text { Factor, } f\end{array}$} & \multirow{2}{*}{$\begin{array}{c}\text { Time Lag, } \phi \\
\text { (min.) }\end{array}$} \\
\hline & Exterior & Interior & & \\
\hline Conventional & 60.56 & 56.98 & 0.941 & 45 \\
\hline U-POFA & 63.51 & 57.98 & 0.913 & 45 \\
\hline G-POFA & 64.95 & 58.26 & 0.897 & 60 \\
\hline 25-LECA 75-OPS & 65.05 & 51.18 & 0.786 & 120 \\
\hline OPS 50-Quarry Dust & 62.55 & 52.17 & 0.834 & 105 \\
\hline Residential Wall & 37.81 & 29.43 & 0.778 & 45 \\
\hline
\end{tabular}




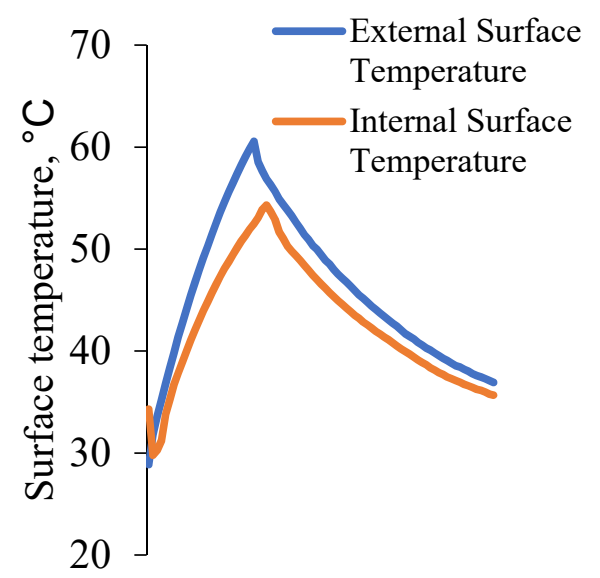

(a)

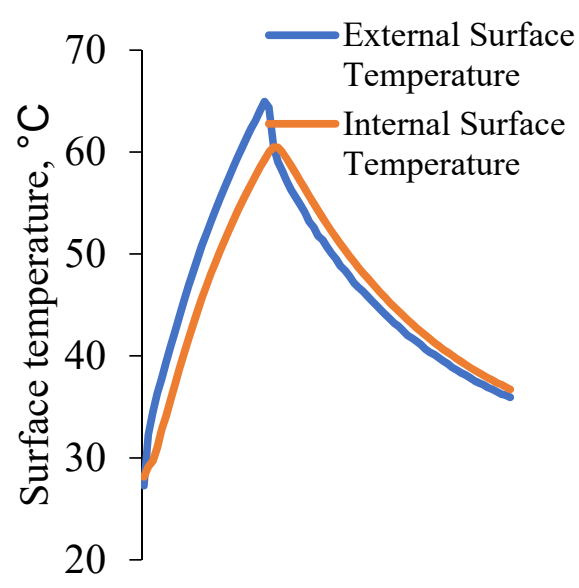

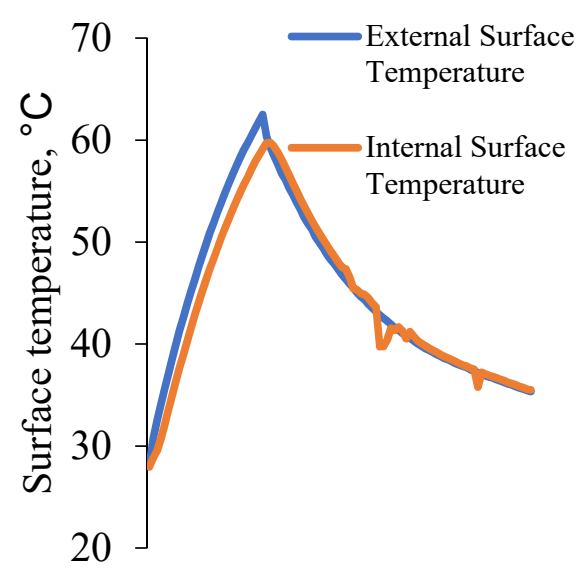

(b)

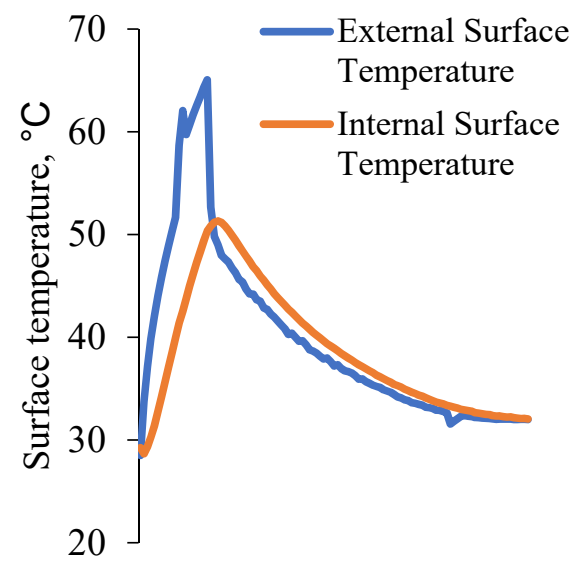

(d)

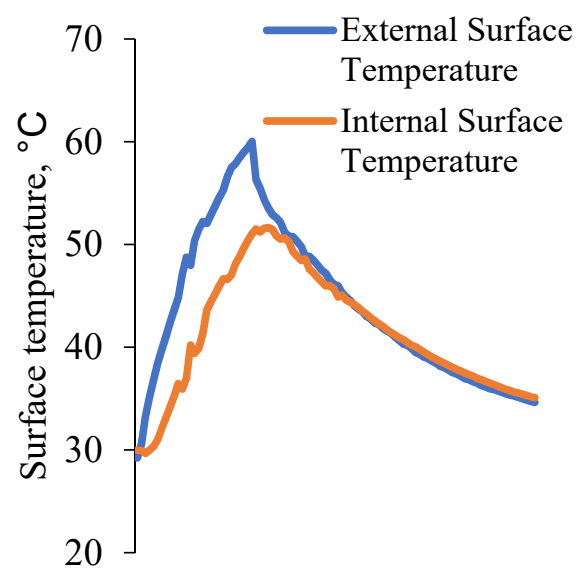

(e)

Figure 4. The external and internal surface temperatures for (a) conventional; (b) U-POFA; (c) GPOFA; (d) 25-LECA 75-OPS; and, (e) OPS 50-Quarry Dust.

\subsubsection{Surface Temperature}

All of the design mixes were able to achieve more than $60{ }^{\circ} \mathrm{C}$ on the exterior wall surface that was exposed to the heat source. Figure 5 shows the exterior wall surface 
temperature history for all of the studied mixes. From the practical example of a residential brick wall surface, the maximum exterior surface temperature was recorded as $37.8^{\circ} \mathrm{C}$, which was lower than the data obtained from the control environment. The 25-LECA 75-OPS specimen was observed to attain its maximum external temperature with the comparatively shortest period, as it possessed the lowest density among all of the investigated small-scaled walls. Furthermore, Figure 6 illustrates the interior surface temperature trend of the proposed design mixes. The peak temperatures were various, ranging from 51 to $58^{\circ} \mathrm{C}$, with an observably similar progressing trend for all mixes. Additionally, it can be noticed that the temperature directly correlates with the concrete density.

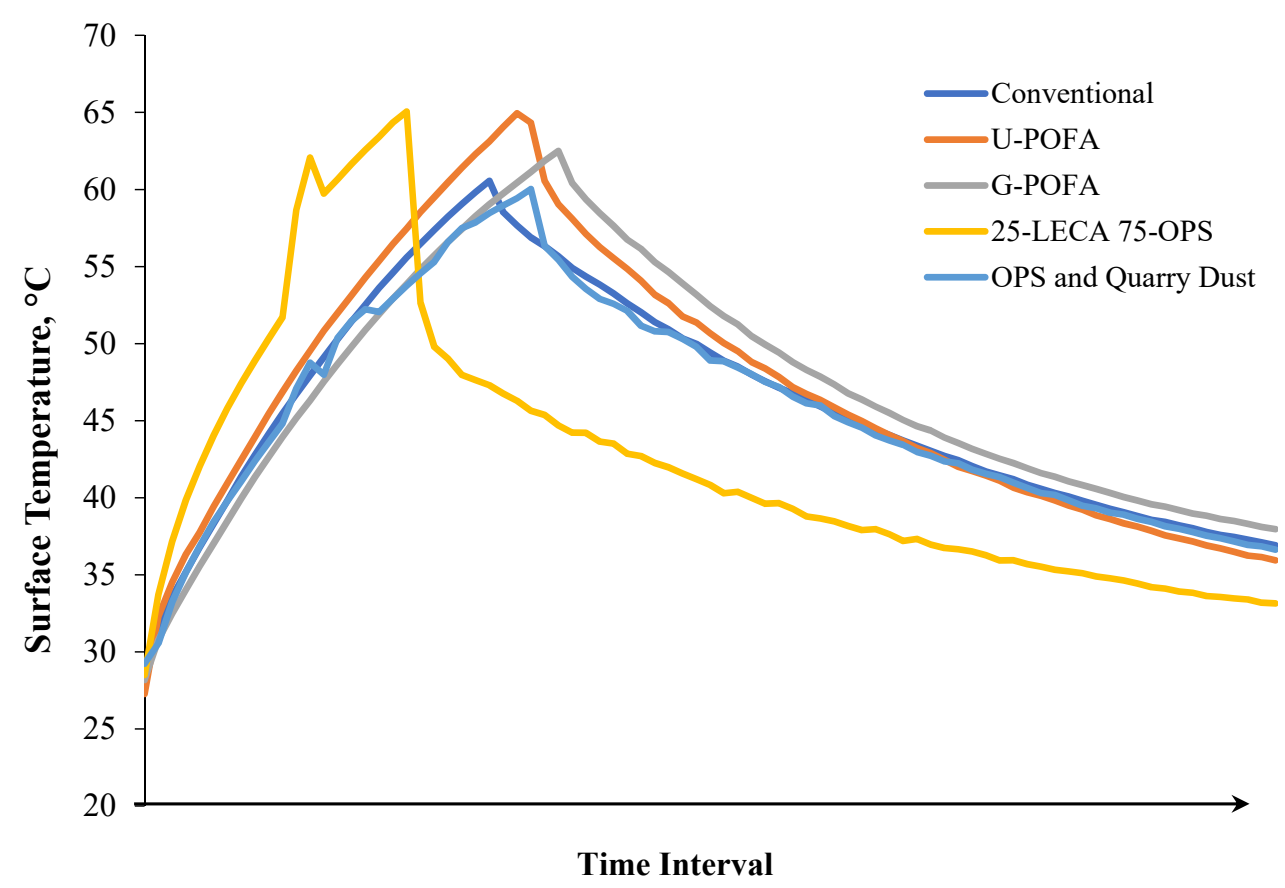

Figure 5. Exterior interior surface temperature of the proposed design mixes for small-scaled wall.

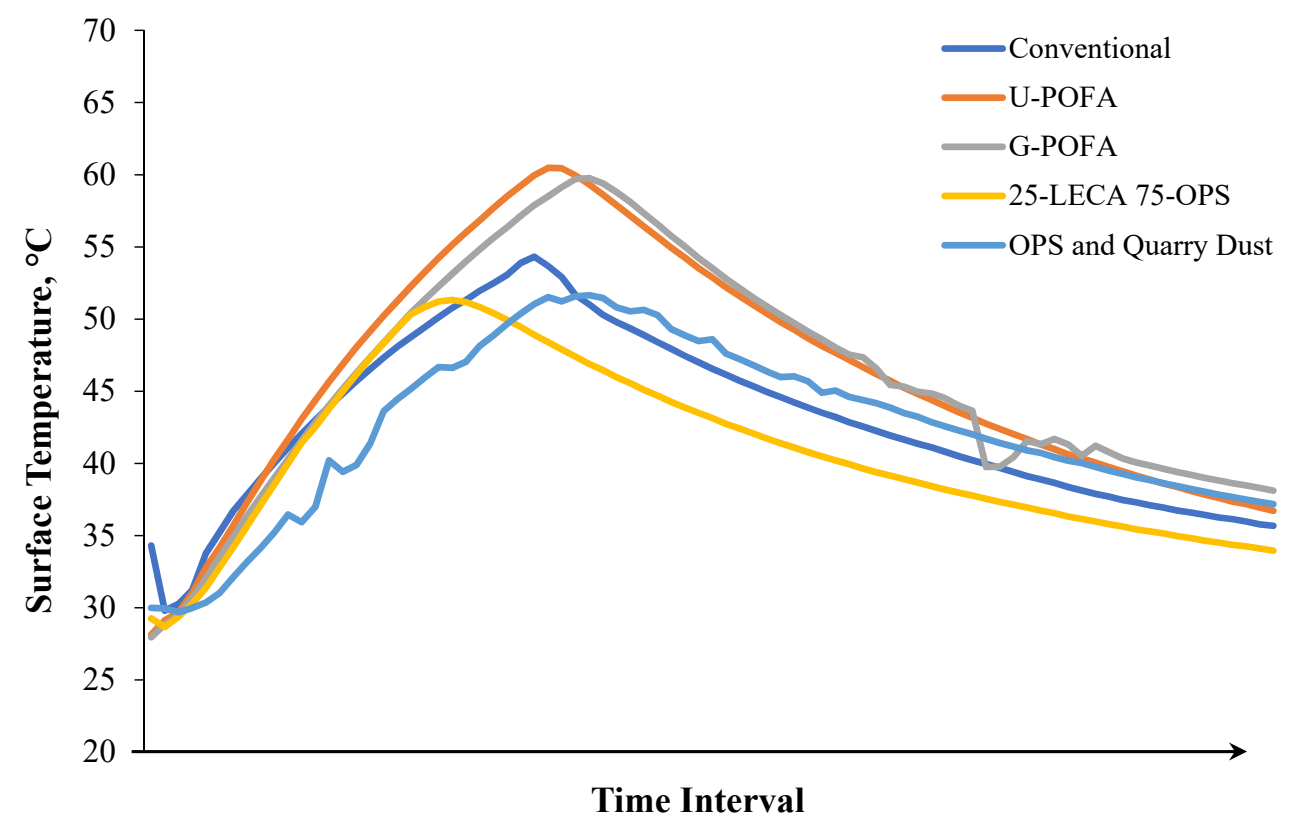

Figure 6. Interior surface temperature of the proposed design mixes for small-scaled wall. 


\subsubsection{Time Lag and Decrement Factor}

Figure 7 and Table 3 display the data that were recorded for the time lag and decrement factor of all of the studied mixes. In Figure 4, the higher density concretes, i.e., conventional, G-POFA, and U-POFA, recorded the higher magnitudes of decrement factor. This trend reveals that most of the heat fluxes had been transferred from outside to indoor environment with a relatively lower rate of heat loss. In contrast, concretes with lower density exhibit a higher rate of heat loss, where the lower decrement factors were discovered from a greater difference between exterior and interior surface temperatures. In terms of time lag, lower density concretes delay the time that is needed for the heat to transfer through the wall more. An approximately double amount of time was needed for a $20 \%$ reduction in the concrete density. This delay promotes the potential of reducing the electricity consumption that is used by the cooling system. The ranking of the maximum exterior wall temperature from the highest to the lowest is 25-LECA 75-OPS > U-POFA > G-POFA > conventional > OPS 50-Quarry Dust, whereas, in terms of interior wall temperature, the rank is U-POFA > G-POFA > conventional > OPS 50-Quarry Dust > 25-LECA 75-OPS.

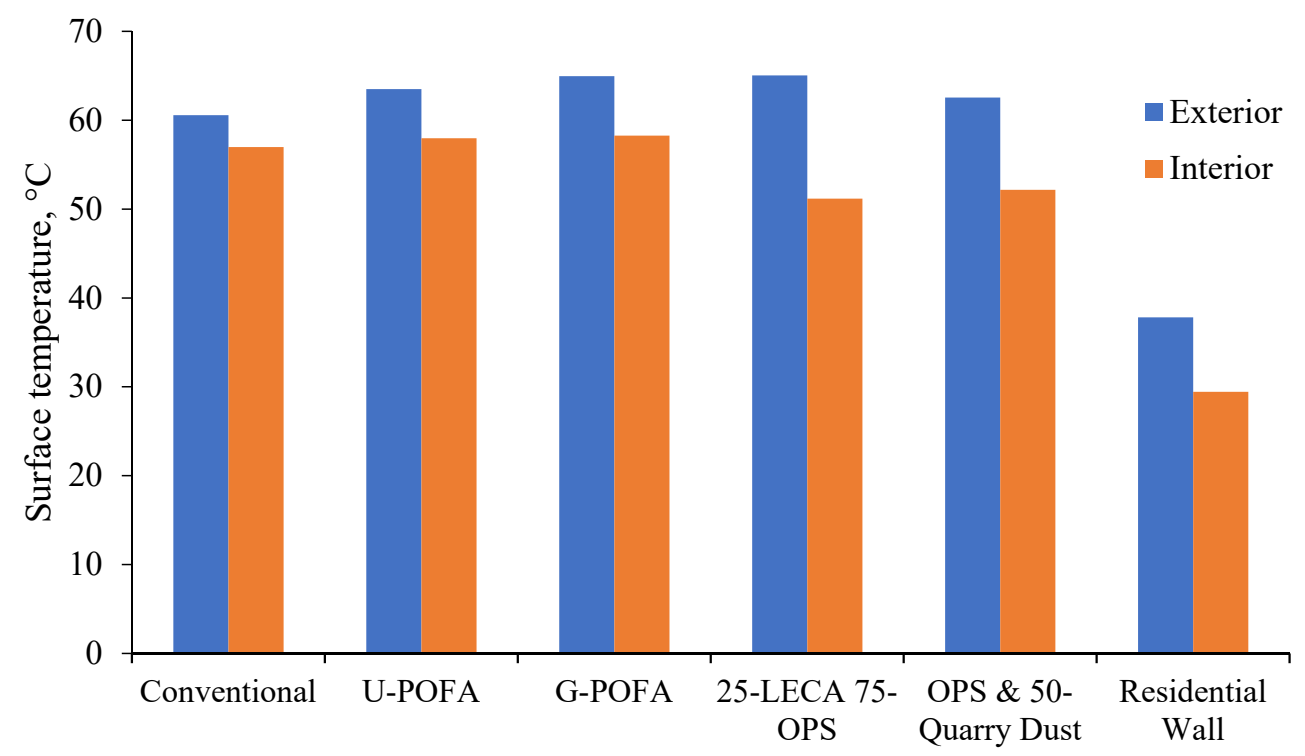

Figure 7. Maximum exterior and interior surface temperatures for the proposed mixes.

From the actual site data collection, a brick wall demonstrated different or much lower surface temperatures, which can be related to the lower solar heat intensity than a light bulb setting that was adopted in the controlled thermal test. Although a lower decrement factor was calculated from the conventional brick wall, a shorter time lag was discovered as compared to those of lightweight concretes. Cement replacement is not significant in resisting the heat that is transferred within the concrete matrix; however, almost the same strength can be obtained from the cement replacement with POFA. This indicates that a lower carbon footprint of POFA can generate an equivalent strength to those with full cement concrete, which is a desirable condition for producing sustainable concrete. For aggregate replacement by LECA or OPS, the strength was gradually decreased, while the thermal properties were superior in restricting the heat transfer within the concrete matrix.

For comparative purposes, the surfaces and ambient temperatures were next recorded for a residential brick wall, as shown in Figure 8. From the outside to internal faces, the wall consisted of weather-proof paint, mortar cover, solid clay brick, mortar cover, and indoor wall paint. This residential wall possessed a lower decrement factor, where a lower indoor wall surface temperature was obtained, similar to LECA + OPS concrete. However, the residential wall was multilayered with several insulating materials and the proposed mixes were tested without covers and paint. The time lag of the residential wall was measured as $45 \mathrm{~min}$, similar to normal weight concretes with approximately the same density. Although 
the conventional brick wall may reduce the heat transfer, the high frequency of heat that is indoor may also induce human thermal discomfort.

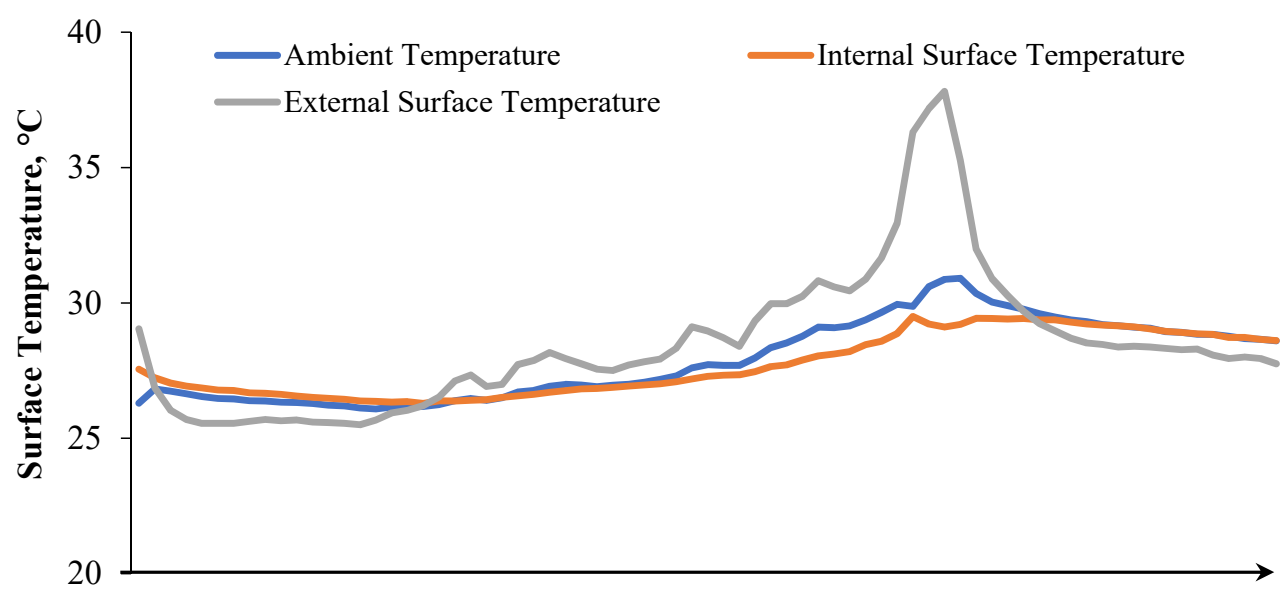

Time Interval

Figure 8. Residential wall surface and ambient temperature fluctuation.

\section{Energy Consumption Analysis}

Numerous factors contribute to the energy consumption in residential buildings. In particular, these include the passive design, ventilation, and thermal properties of building materials. From the experiments, it can be deduced that, generally, lightweight concretes have better thermal performance than normal-weight concrete, as shown in Figure 5, which could be potentially exploited to achieve a reduction in energy consumption in a later stage of the building performance during service lifespan. From the material viewpoint, air pockets in the concrete matrix may significantly reduce the heat transfer, while an increase in air pockets reduces the concrete density.

In order to attain human thermal comfort, it is well-recognized that the majority of the electricity of residential buildings is consumed, particularly for heating and cooling systems. Furthermore, energy-saving on heating and cooling services is the chief concern in the current lifestyle sustainability trend. Technology, like automated outdoor compressor units, can be activated when the indoor temperature is found to be lower than the set temperature and it ceases to operate once the desired temperature is achieved. From the material aspect, the thermal properties of building materials should be primarily taken into consideration in the design stage for better energy efficiency planning. The decrement factor and time lag of the walls of a structure may reduce the operation period of the compressor, leading to significant energy saving.

\subsection{OTTV Calculation of Concrete Wall}

The correlation of concrete density, thermal transmittance value, and concrete strength is yet to be established in current research trend; most of them have investigated the concrete density and thermal conductivity. In this section, the preliminary study of OTTV calculation with different concrete density and strength is presented. According to Equation (2), Malaysian OTTV is calculated with a mean WWR of 0.06 , window solar radiation of 8.85 , shading coefficient of 0.5 , and $\alpha$ of 0.76 . Table 4 shows the OTTV calculation for the conventional wall and unplastered concrete wall. 
Table 4. Overall Thermal Transfer Value (OTTV) calculation of different concrete density and strength.

\begin{tabular}{|c|c|c|c|c|c|c|}
\hline Ref & Design Mix & $\begin{array}{c}\text { Concrete Density, } \mathrm{kg} / \mathrm{m}^{3} \text { (Thermal } \\
\left.\text { Conductivity, } \mathrm{W} / \mathrm{mK}^{2}\right)\end{array}$ & Cover Details & $\begin{array}{c}\text { Concrete } \\
\text { Strength, MPa }\end{array}$ & $\begin{array}{l}\text { U-Value, } \\
\text { W/m } / \mathbf{m}^{2} \mathrm{~K}\end{array}$ & $\begin{array}{l}\text { OTTV, } \\
\text { W/m }\end{array}$ \\
\hline \multirow{5}{*}{ [27] } & $220 \mathrm{~mm}$ brickwork & - & Unplastered & $3.5^{*}$ & 2.3 & 37.20 \\
\hline & $220 \mathrm{~mm}$ brickwork & - & $13 \mathrm{~mm}$ dense plaster & $3.5^{*}$ & 2.1 & 34.47 \\
\hline & $105 \mathrm{~mm}$ brickwork $+50 \mathrm{~mm}$ urea-formaldehyde foam & - & $13 \mathrm{~mm}$ lightweight plaster & $3.5 *$ & 0.55 & 13.32 \\
\hline & $200 \mathrm{~mm}$ heavyweight concrete block $+25 \mathrm{~mm}$ air gap & - & $10 \mathrm{~mm}$ plasterboard & & 1.8 & 30.38 \\
\hline & $200 \mathrm{~mm}$ lightweight concrete block + $25 \mathrm{~mm}$ air gap & - & $10 \mathrm{~mm}$ plasterboard & & 0.68 & 15.10 \\
\hline \multirow[t]{2}{*}{ [28] } & Common brick $215 \times 96 \times 70 \mathrm{~mm}, 1.04 \mathrm{~W} / \mathrm{mK}$ conductivity & - & & 25 & 10.8 & 153.19 \\
\hline & & $1192(0.41)$ & & 10.38 & 4.02 & 60.67 \\
\hline \multirow{6}{*}{ [29] } & & $1354(0.50)$ & & 10.50 & 4.90 & 72.68 \\
\hline & Foamed concrete (use thickness of $102 \mathrm{~mm}$ ) & $1409(0.54)$ & & 13.43 & 5.29 & 78.00 \\
\hline & & $1506(0.55)$ & & 17.23 & 5.39 & 79.37 \\
\hline & & $1594(0.57)$ & & 20.20 & 5.59 & 82.10 \\
\hline & Brick & $2067(0.90)$ & & & 8.82 & 126.17 \\
\hline & Block & $1832(0.60)$ & & & 5.88 & 86.05 \\
\hline \multirow{4}{*}{ [30] } & & $1291(0.47)$ & & 8.3 & 4.61 & 68.72 \\
\hline & Oil molm sholl formed cromolymor concrote & $1467(0.50)$ & & 13.5 & 4.90 & 72.68 \\
\hline & & $1791(0.58)$ & & 30.1 & 5.69 & 83.46 \\
\hline & Normal & $2240(2.24)$ & & & 21.96 & 305.47 \\
\hline \multirow{4}{*}{ [31] } & Magnetite & $3650(2.57)$ & & & 25.20 & 349.68 \\
\hline & Graphite & $1890(3.52)$ & & & 34.51 & 476.71 \\
\hline & Graphite + Magnetite & $2810(3.85)$ & & & 37.75 & 520.92 \\
\hline & Steel fiber & $2330(2.57)$ & & & 26.96 & 373.69 \\
\hline \multirow{9}{*}[32]{} & \multirow{9}{*}{$\begin{array}{l}\text { Silica fume ( } 7.5 \text { and } 15 \% \text { cement replacement); fly ash and } \\
\text { blast furnace (15 and 30\% cement replacement) }\end{array}$} & $2350(1.16)$ & & 53.44 & 11.37 & 160.96 \\
\hline & & $2335(1.05)$ & & 53.77 & 10.29 & 146.23 \\
\hline & & $2340(1.08)$ & & 39.47 & 10.59 & 150.32 \\
\hline & & $2290(0.95)$ & & 31.67 & 9.31 & 132.86 \\
\hline & & 2355 (1.09) & & 42.82 & 10.69 & 151.69 \\
\hline & & $2340(1.04)$ & & 41.50 & 10.20 & 145.00 \\
\hline & & $2330(0.99)$ & & 52.70 & 9.71 & 138.31 \\
\hline & & 2345 (1.12) & & 55.02 & 10.98 & 155.64 \\
\hline & & $2300(0.97)$ & & 33.07 & 9.51 & 135.58 \\
\hline
\end{tabular}

* not specified, minimum code requirements. 
According to MS1525 [25], the wall OTTV value of commercial building of $4000 \mathrm{~m}^{2}$ and above should be controlled at around $50 \mathrm{~W} / \mathrm{m}^{2}$. The plastered walls shown in Table 4 passed the requirement, while unplastered concrete walls did not pass the requirement using $102 \mathrm{~mm}$ wall thickness. In order to achieve $17 \mathrm{MPa}$ of structural concrete, unplastered structural concrete wall is insufficient for providing thermal protection from this envelope, as it is almost reached $80 \mathrm{~W} / \mathrm{m}^{2}$ OTTV value. Figure 9 shows the correlation of concrete density, concrete strength, and U-value. As a summary, by combining the regression lines in Figure 9, the correlation can be represented by Equation (5).

$$
U_{c}=0.904 \times \sigma_{c}^{0.7}
$$

where $U_{c}$ is the transmittance value and $\sigma_{c}$ is the concrete compressive strength.

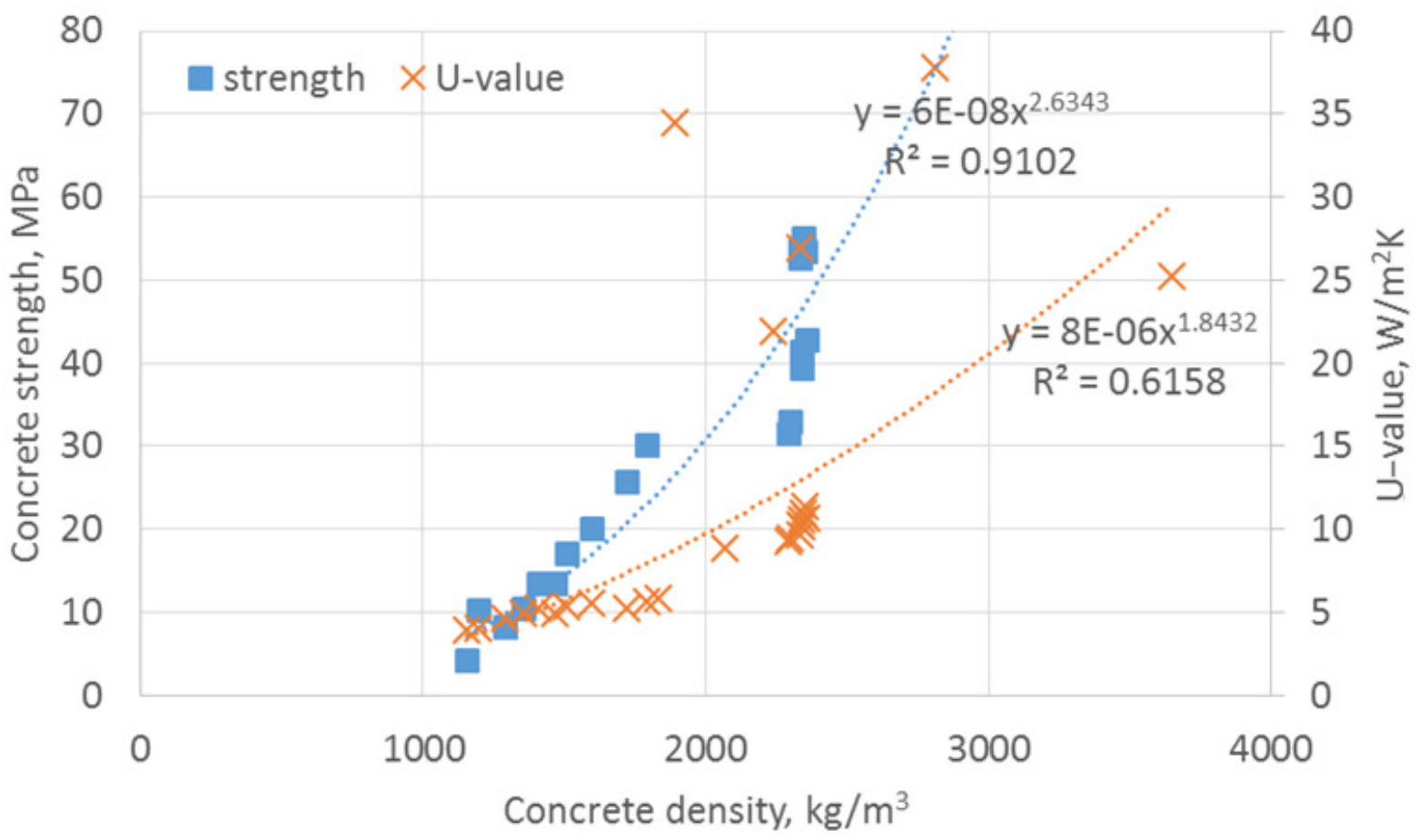

Figure 9. Correlation of concrete density, strength, and U-value from previous studies.

From the Equation (5), it is shown that the correlation is nonlinear and works through exponential. The coefficient may vary from study to study as the other parameters governing in the U-value, namely thickness and plastering materials. From Figure 9, it is revealed that $1700 \mathrm{~kg} / \mathrm{m}^{3}$ lightweight concrete density can achieve the structural concrete application.

\subsection{Cooling Load}

The cooling load is calculated using Equation (3) in a meter square area of wall. Using the temperature difference from residential wall in current study, as shown in Table 5, the required cooling load for the proposed design mix was lower for those with lower density, but it achieved structural concrete properties. This cooling load is directed to the energy consumption of air-conditioning system. Structural lightweight concrete with oil palm shells and expanded clay only required half of the cooling load as compared to conventional concrete. 
Table 5. Cooling load of the proposed design mixes.

\begin{tabular}{ccc}
\hline Specimen & $\begin{array}{c}\text { U-value (Equation (5)) } \\
\mathbf{W} / \mathbf{m}^{\mathbf{2}} \mathbf{K}\end{array}$ & $\begin{array}{c}\text { Cooling Load (Equation (4)) } \\
\mathbf{W} / \mathbf{m}^{\mathbf{2}}\end{array}$ \\
\hline Conventional & 15.15 & 126.97 \\
U-POFA & 15.00 & 125.70 \\
G-POFA & 14.44 & 121.04 \\
25-LECA 75-OPS & 6.62 & 55.50 \\
OPS 50-Quarry Dust & 7.18 & 60.16 \\
\hline
\end{tabular}

\subsection{Case Study on Potential Energy Saving}

There are no data for the available energy consumption of an air-conditioning system with certain temperature as a set temperature in Malaysia climate. Therefore, previous data from previous study were adopted where the external maximum ambient temperature was set at $32{ }^{\circ} \mathrm{C}$. It can be noticed that the 25-LECA 75-OPS specimen in this study demonstrated a decrement factor of $21.4 \%$, from which a residential unit enclosed by external walls constructed by this design mix has the energy-saving potential of up to $54.8 \%$ when compared to units that are enclosed by conventional concrete walls. The concept behind this estimation is based on the difference in room temperatures of the residential units. For example, in a day where the outdoor temperature is at $31^{\circ} \mathrm{C}$, rooms that are enclosed by 25-LECA 75-OPS concrete walls may achieve a temperature as low as $24.4{ }^{\circ} \mathrm{C}$, while rooms enclosed by conventional concrete walls could experience an indoor temperature of $29.2{ }^{\circ} \mathrm{C}$. The lower indoor room temperature allows the employment of the automated compressor of the air-conditioning device to operate at a minimum time as it ceases to operate once the thermostat determines that the desired indoor temperature is reached. Adopting a similar mode of analysis, Table 6 tabulates the energy potential of all the studied specimens when they are placed in the aforementioned scenario. The time lag of the wall materials may also delay the time for the indoor temperature to escalate due to the increasing outdoor temperature during the day, which potentially reduces the period of operation for air conditioners. In terms of energy-saving potential, the currently studied materials are ranked from the highest performance to the lowest as 25-LECA 75-OPS > OPS 50-Quarry Dust > G-POFA > U-POFA > conventional. Despite the lower strength achieved by lightweight concrete as compared to others, it possessed the highest energy saving and achieved the structural concrete specifications.

Table 6. Potential energy saving with an outdoor temperature of $31^{\circ} \mathrm{C}$.

\begin{tabular}{ccccc}
\hline Specimen & Strength, MPa & Decrement Factor, \% & Indoor Temperature, ${ }^{\circ}$ C & Energy Saving Potential, \% \\
\hline Conventional & 56.1 & 5.9 & 29.17 & 14.64 \\
U-POFA & 55.3 & 8.7 & 28.30 & 21.6 \\
G-POFA & 52.4 & 10.3 & 27.81 & 25.52 \\
25-LECA 75-OPS & 17.2 & 21.4 & 24.37 & 53.04 \\
OPS 50-Quarry Dust & 19.3 & 16.6 & 25.85 & 41.2 \\
\hline
\end{tabular}

\section{Conclusions}

Lightweight concretes of various design mixes were assessed for the thermal and strength performances for energy-saving prospects as building envelop material applications. In particular, compressive strength, time lag, decrement factor, and thermal energy analysis were examined. The considered mixes were those with conventional Ordinary Portland cement as control, G-POFA $\left(880 \mathrm{~kg} / \mathrm{m}^{3}\right.$ density), U-POFA $\left(1080 \mathrm{~kg} / \mathrm{m}^{3}\right.$ density), 25-LECA 75-OPS (25\% lightweight expanded clay aggregate and $75 \%$ oil palm shell), and OPS 50-QD (oil palm shell and 50\% quarry dust). Several conclusions, as presented below, can be drawn from this investigation. 
i. All of the proposed design mixes achieved the minimum structural concrete requirement of 17 MPa compressive strength stated by the ACI specification.

ii. From scaled wall and site tests, the ranking of the time lags from the highest to the lowest was 25-LECA 75-OPS > OPS 50-Quarry Dust > G-POFA > U-POFA = conventional $=$ residential wall. The mix of 75-LECA 25-OPS exhibited the lowest decrement factor and the longest time lag, which are both beneficial in maintaining indoor thermal comfort with the least heat transferred through the wall.

iii. For energy saving, concrete with a better (lower) decrement factor displays a higher percentage of potential energy saving. The energy-saving was ranked from the highest performance to the lowest as 25-LECA 75-OPS > OPS 50-Quarry Dust > G-POFA $>$ U-POFA > conventional. More than 50\% energy-saving was found in the lowest density 75-LECA 25-OPS specimen.

Author Contributions: N.C. and Y.H.L.; Data curation, Y.Y.L., A.B.H.K., R.F., N.V. and Y.V.; Formal analysis, Y.H.L., M.A. and Y.Y.L.; Funding acquisition, M.A., R.F., N.V. and Y.V.; Investigation, N.C., Y.H.L. and A.B.H.K.; Methodology, N.C., M.A. and Y.Y.L.; Project administration, M.A., R.F., N.V. and Y.V.; Resources, M.A., Y.Y.L., A.B.H.K., R.F., N.V. and Y.V.; Software, A.B.H.K. and R.F.; Supervision, Y.H.L. and Y.Y.L.; Validation, M.A., N.V. and Y.V.; Visualization, Y.Y.L., A.B.H.K. and R.F.; Writingoriginal draft, N.C., Y.H.L., M.A., Y.Y.L. and A.B.H.K.; Writing-review \& editing, N.C., Y.H.L., M.A., Y.Y.L., A.B.H.K., R.F., N.V. and Y.V. All authors have read and agreed to the published version of the manuscript.

Funding: The research is partially funded by the Russian Federation as part of World-class Research Center program: Advanced Digital Technologies (contract No. 075-15-2020-934 dated 17 November 2020).

Institutional Review Board Statement: Not applicable.

Informed Consent Statement: Not applicable.

Data Availability Statement: Data sharing not applicable.

Acknowledgments: The authors would like to acknowledge the supports provided by Curtin University Malaysia, Universiti Malaysia Sarawak and Ministry of Higher Education through FRGS Grant (FRGS/1/2019/TK10/UNIMAS/02/4). Also, the authors gratefully acknowledge the support given by Deanship of Scientific Research at Prince Sattam bin Abdulaziz University, Alkharj, Saudi Arabia; Moscow Automobile and Road Construction University, Moscow, Russia; and the Department of Civil Engineering, Faculty of Engineering and IT, Amran University, Yemen, for this research.

Conflicts of Interest: The authors declare no conflict of interest.

\section{References}

1. Jhatial, A.A.; Goh, W.I.; Mohamad, N.; Rind, T.A.; Sandhu, A.R. Development of Thermal Insulating Lightweight Foamed Concrete Reinforced with Polypropylene Fibres. Arab. J. Sci. Eng. 2020, 45, 4067-4076. [CrossRef]

2. Garay, R.; Uriarte, A.; Apraiz, I. Performance assessment of thermal bridge elements into a full scale experimental study of a building façade. Energy Build. 2014, 85, 579-591. [CrossRef]

3. Amran, M.; Fediuk, R.; Vatin, N.; Lee, Y.H.; Murali, G.; Ozbakkaloglu, T.; Klyuev, S.; Alabduljabber, H. Fibre-reinforced foamed concretes: A review. Materials 2020, 13, 4323. [CrossRef] [PubMed]

4. Mugahed Amran, Y.H.; Alyousef, R.; Alabduljabbar, H.; Khudhair, M.H.R.; Hejazi, F.; Alaskar, A.; Alrshoudi, F.; Siddika, A. Performance properties of structural fibred-foamed concrete. Results Eng. 2020, 5, 100092. [CrossRef]

5. Amran, M.; Lee, Y.H.; Vatin, N.; Fediuk, R.; Poi-Ngian, S.; Lee, Y.Y.; Murali, G. Design efficiency, characteristics, and utilization of reinforced foamed concrete: A review. Crystals 2020, 10, 948. [CrossRef]

6. Ahmad Zawawi, M.N.A.; Muthusamy, K.P.P. Abdul Majeed, A.; Muazu Musa, R.; Mokhtar Albshir Budiea, A. Mechanical properties of oil palm waste lightweight aggregate concrete with fly ash as fine aggregate replacement. J. Build. Eng. 2020, 27, 100924. [CrossRef]

7. Shafigh, P.; Jumaat, M.Z.; Mahmud, H. Oil palm shell as a lightweight aggregate for production high strength lightweight concrete. Constr. Build. Mater. 2011, 25, 1848-1853. [CrossRef]

8. Shafigh, P.; Salleh, S.; Ghafari, H.; Bin Mahmud, H. Oil palm shell as an agricultural solid waste in artificial lightweight aggregate concrete. Eur. J. Environ. Civ. Eng. 2018, 22, 165-180. [CrossRef] 
9. Ismail, K.N.; Halim, N.F. Strength and microstructural study of lightweight aggregate concrete (Lwac) using lightweight expended clay aggregates (leca). Mater. Sci. Forum 2020, 1010, 678-683. [CrossRef]

10. Jin, X.; Zhang, X.; Cao, Y.; Wang, G. Thermal performance evaluation of the wall using heat flux time lag and decrement factor. Energy Build. 2012, 47, 369-374. [CrossRef]

11. Thongtha, A.; Maneewan, S.; Punlek, C.; Ungkoon, Y. Investigation of the compressive strength, time lags and decrement factors of AAC-lightweight concrete containing sugar sediment waste. Energy Build. 2014, 84, 516-525. [CrossRef]

12. Suwansumrit, P.; Chunkao, K.; Bualert, S.; Chanthasoon, C.; Semvimol, N. Lag Time of Heat Conduction in Conditions of Growing Greenery Cover on Flattop-Concrete Roof of Single-Room House with Lightweight-Concrete Walls as Constructed on Narrow Space in Bangkok. Mod. Appl. Sci. 2015, 9, 92. [CrossRef]

13. Asan, H. Numerical computation of time lags and decrement factors for different building materials. Build. Environ. 2006, 41, 615-620. [CrossRef]

14. Oktay, H.; Yumrutaş, R.; Akpolat, A. Mechanical and thermophysical properties of lightweight aggregate concretes. Constr. Build. Mater. 2015, 96, 217-225. [CrossRef]

15. Toure, P.M.; Dieye, Y.; Gueye, P.M.; Sambou, V.; Bodian, S.; Tiguampo, S. Experimental determination of time lag and decrement factor. Case Stud. Constr. Mater. 2019, 11, e00298. [CrossRef]

16. Tay, L.T.; Lee, Y.Y.; Lee, Y.H.; Kueh, A.B.H. Compressive and Flexural Strengths of Mortar with Silica Aerogel Powder; Springer: Singapore, 2021.

17. Alavéz-Ramírez, R.; Chiñas-Castillo, F.; Morales-Domínguez, V.J.; Ortiz-Guzmán, M.; Caballero-Montes, J.L.; Caballero-Caballero, M. Thermal lag and decrement factor of constructive component reinforced mortar channels filled with soil-cement-sawdust. Indoor Built Environ. 2018, 27, 466-485. [CrossRef]

18. Oktay, H.; Yumrutas, R.; Argunhan, Z. An experimental investigation of the effect of thermophysical properties on time lag and decrement factor for building elements. Gazi Univ. J. Sci. 2020, 33, 492-508. [CrossRef]

19. Wang, T.P.; Wang, L.B. The effects of transparent long-wave radiation through glass on time lag and decrement factor of hollow double glazing. Energy Build. 2016, 117, 33-43. [CrossRef]

20. Jaturapitakkul, C.; Kiattikomol, K.; Tangchirapat, W.; Saeting, T. Evaluation of the sulfate resistance of concrete containing palm oil fuel ash. Constr. Build. Mater. 2007, 21, 1399-1405. [CrossRef]

21. Zeyad, A.M.; Megat Johari, M.A.; Tayeh, B.A.; Yusuf, M.O. Pozzolanic reactivity of ultrafine palm oil fuel ash waste on strength and durability performances of high strength concrete. J. Clean. Prod. 2017, 144, 511-522. [CrossRef]

22. Ahmad, M.R.; Chen, B. Experimental research on the performance of lightweight concrete containing foam and expanded clay aggregate. Compos. Part B Eng. 2019, 171, 46-60. [CrossRef]

23. Ji, T.; Zheng, D.D.; Chen, X.F.; Lin, X.J.; Wu, H.C. Effect of prewetting degree of ceramsite on the early-age autogenous shrinkage of lightweight aggregate concrete. Constr. Build. Mater. 2015, 98, 102-111. [CrossRef]

24. Surapong, C. Developing Countries Experience With Building Energy Codes and Energy Efficiency in Existing Buildings; Asian Institute of Technology: Pathum Thani, Thailand, 2006.

25. MS1525. Energy Efficiency and Use of Renewable Energy for Non-Residential Buildings—Code of Practice; Malaysian Standards: Cyberjaya, Malaysia, 2007.

26. Wang, N.; Zhang, J.; Xia, X. Energy consumption of air conditioners at different temperature set points. Energy Build. 2013, 65, 412-418. [CrossRef]

27. Laughton, M.; Warne, D. Electrical Engineer's Reference Book, 16th ed.; Elsevier Science: Oxford, UK, 2003.

28. Kai Lim, B. Technical Data of Brick. Available online: http:/ / www.kialim.com.my/bricks-spec.php (accessed on 30 March 2021).

29. Johnson Alengaram, U.; Al Muhit, B.A.; Bin Jumaat, M.Z.; Jing, M.L.Y. A comparison of the thermal conductivity of oil palm shell foamed concrete with conventional materials. Mater. Des. 2013, 51, 522-529. [CrossRef]

30. Liu, M.Y.J.; Alengaram, U.J.; Jumaat, M.Z.; Mo, K.H. Evaluation of thermal conductivity, mechanical and transport properties of lightweight aggregate foamed geopolymer concrete. Energy Build. 2014, 72, 238-245. [CrossRef]

31. Wadsö, L.; Karlsson, J.; Tammo, K. Thermal Properties of Concrete with Various Aggregates. submitted for publication. 2012.

32. Demirboğa, R. Thermal conductivity and compressive strength of concrete incorporation with mineral admixtures. Build. Environ. 2007, 42, 2467-2471. [CrossRef] 